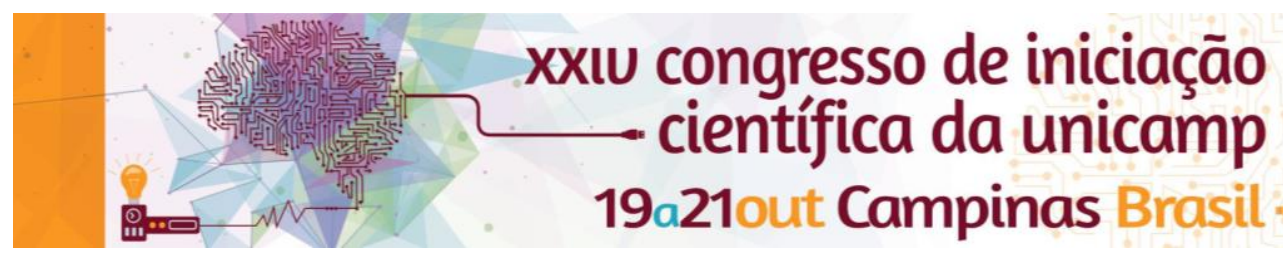

\title{
Germination of seeds dispersed by frugivorous birds in different environmental conditions.
}

\author{
Alina van Dijk*, Veridiana Angeluzzi Jardim, Wesley Rodrigues Silva.
}

\begin{abstract}
By consuming fruits, frugivorous animals perform an important interaction: seed dispersal. As the seeds pass through their digestive system, there are chemical and physical changes that may interfere in the germination process, eighter by reducing or increasing it. Many studies use laboratory techniques to understand the effect of vertebrate's digestive system on seeds by comparing germination of dispersed with no dispersed ones. However, such studies often lack on real field conditions evaluation. In this study, the germination of endozoochory dispersed seeds by frugivorous birds was investigated both in field and laboratory conditions. Dispersed seeds were collected and germinated in three diferent conditions: field, germination chamber and greenhouse. The environment conditions affected the number of germinated species, total number of seed germination, duration and speed of germination. This data shows the importance of considering envirolmental conditions while interpretating seed germination by seed dispersal processes.
\end{abstract}

\section{Key words:}

seed dispersal, mutualism, conditions of germination.

\section{Introduction}

The relationship between frugivorous animals and the fruits they feed on is commonly considered a mutualism. By consuming the fruit, frugivorous animals obtain nutrients, while plants have the benefits of having their seeds dispersed far from the plant-mother ${ }^{1 .}$ A second implicit advantage would be the increase in germination of seeds after going through the digestive system of vertebrates $^{2}$, since it could cause mechanical and/or chemical changes on the seed coating structure and remove chemical compounds in the pulp that could inhibit the germination. Several studies report the effects of scarification caused by frugivorous seed dispersal, mostly comparing lab results of germination on both dispersed seeds and not dispersed ones ${ }^{3}$. This type of experimental comparison, however, may not be able to fully evaluate the effect of the seed passage through the digestive system and, by extension, the role of frugivorous animals on the dispersion process. It is likely that just comparing the germination of non-dispersed and dispersed seeds in laboratories and greenhouses is not enough to check their germination on field conditions, where they would naturally be deposed, due to several filters and environmental barriers (both biotic and abiotic) that could synergistically interfere in order to reduce the success of germination and establishment of new plants ${ }^{4,5}$.

\section{Results and Discussion}

The dispersed seeds were collected from 50 collectors located in two semi-deciduous forest fragments, located at the campus of the Universidade Estadual de Campinas, Brazil. The content of each collector was taken once by month, selected and then separated into three groups. The first was sown in a germination chamber at the Department of Animal Biology, the second in a greenhouse at the Department of Plant Biology and the third directly in the soil of the field which belonged to the same environment where the seeds were originally collected. Germination was evaluated during five months from sown.
A higher number of species germinated on the greenhouse, which also presented a higher quantity of total seed germination. Seeds sown on field condition needed a longer period until germination, as elucidated in Table 1.

Table 1. Comparison between methods

\begin{tabular}{|c|c|c|c|}
\hline & $\begin{array}{c}\text { Germination } \\
\text { chamber }\end{array}$ & Greenhouse & Field \\
\hline Germinated species & 5 & 12 & 5 \\
\hline $\begin{array}{c}\text { Total number of } \\
\text { germinated seeds }\end{array}$ & 22 & 111 & 10 \\
\hline $\begin{array}{c}\text { Average duration } \\
\text { (days) }\end{array}$ & 45,2 & 45,5 & 105,2 \\
\hline $\begin{array}{c}\text { Average germination } \\
\text { speed } \\
\text { (seeds/ day) }\end{array}$ & 0,3 & 0,5 & 0,1 \\
\hline
\end{tabular}

\section{Conclusions}

This study highlights the importance of taking into account the conditions and the environment used in the evaluation of seed germination processes in order to understand the real effects of vertebrate-plant interaction in seed dispersal.

\section{Acknowledgements}

To Dr. José Roberto Trigo, Dr. Rafael Silva Oliveira and the whole Vertebrate-Plant Interaction Lab (LIVEP) team for the help. To CNPq and Unicamp for funding and support.

\footnotetext{
${ }^{1}$ Howe, H. F e Smallwood, J. Annual Review of ecology and Systematics 1982, 13:201-228

${ }^{2}$ Samuels, I.A e Levey, D. J. Functional Ecology, 2005, 19:365-368F

${ }^{3}$ Traveset, A. e Verdú, M. Seed dispersal and frugivory: ecology, evolution and conservation, 2002, In: D. J. Levey; W. R. Silva e M. Galetti (eds). Pp. 339-350. Wallingford, UK, CABI Publ.

${ }^{4}$ Schupp, E. W. Oecologia, 1988, 76: 525-530.

${ }^{5}$ Clark, C.J.; Poulsen, J. R e Levey, D. J. Plos One. 2013. DOI:

10.1371/journal.pone.0063330.
} 